\title{
Stress-Induced p38 Mitogen-Activated Protein Kinase Activation Mediates $\kappa$-Opioid-Dependent Dysphoria
}

\author{
Michael R. Bruchas, ${ }^{1}$ Benjamin B. Land, ${ }^{2}$ Megumi Aita, ${ }^{1}$ Mei Xu, ${ }^{1}$ Sabiha K. Barot,,${ }^{2}$ Shuang Li, ${ }^{1}$ and Charles Chavkin ${ }^{1,2}$ \\ ${ }^{1}$ Department of Pharmacology and ${ }^{2}$ Graduate Program in Neurobiology and Behavior, University of Washington, Seattle, Washington 98195-7280
}

The molecular mechanisms mediating stress-induced dysphoria in humans and conditioned place aversion in rodents are unknown. Here, we show that repeated swim stress caused activation of both $\kappa$-opioid receptor (KOR) and p38 mitogen-activated protein kinase (MAPK) coexpressed in GABAergic neurons in the nucleus accumbens, cortex, and hippocampus. Sites of activation were visualized using phosphoselective antibodies against activated $\kappa$ receptors (KOR-P) and against phospho-p38 MAPK. Surprisingly, the increase in P-p38-IR caused by swim-stress exposure was completely KOR dependent; P-p38-IR did not increase in KOR $(-/-)$ knock-out mice subjected to the same swim-paradigm or in wild-type mice pretreated with the KOR antagonist norbinaltorphimine. To understand the relationship between p38 activation and the behavioral effects after KOR activation, we administered the p38 inhibitor SB203580 [4-(4fluorophenyl)-2-(4-methylsulfonylphenyl)-5-(4-pyridyl)-1H-imidazole (i.c.v.)] and found that it selectively blocked the conditioned place aversion caused by the $\kappa$ agonist trans-3,4-dichloro- $N$-methyl- $N$-[2-(1-pyrrolidinyl)cyclohexyl]-benzeneacetamide (U50488) and the KOR-dependent swim stress-induced immobility while not affecting $\kappa$-opioid analgesia or nonselectively affecting associative learning. We found that the mechanism linking KOR and $\mathrm{p} 38$ activation in vivo was consistent with our previous in vitro data suggesting that $\beta$-arrestin recruitment is required; mice lacking G-protein-coupled receptor kinase 3 also failed to increase p-p38-IR after KOR activation in vivo, failed to show swim stress-induced immobility, or develop conditioned place aversion to U50488. Our results indicate that activation of p38 MAPK signaling by the endogenous dynorphin- $\kappa$-opioid system likely constitutes a key component of the molecular mechanisms mediating the aversive properties of stress.

Key words: dynorphin; G-protein-coupled receptor kinase; $\beta$-arrestin; aversion; stress-induced immobility; drug addiction; p38 MAPK; $\kappa$-opioid receptor

\section{Introduction}

Exposure to behavioral stressors activates several neuropeptide systems, including the endogenous opioid system in the brain and spinal cord and the CRF/ACTH systems in the brain and hypothalamic pituitary axis (Herman et al., 2004; de Kloet et al., 2005). Orchestration of the stress response is necessary for survival, but chronic stress can have adverse effects, including increased risk of depression in humans, increased propensity to participate in drug-seeking behavior, and increased drug-craving in drug-dependent humans and rodents (Holsboer, 2000; McLaughlin et al., 2003a, 2006; Beardsley et al., 2005). The neuronal mechanisms of these effects are under active investigation, and new evidence suggests that the dynorphin- $\kappa$-opioid system is one of the major components of this response (Mello and Mendelson, 1997; Carlezon et al., 1998; Kreek and Koob, 1998; McLaughlin et al., 2003a, 2006; Beardsley et al., 2005). Dynor-

Received Aug. 17, 2007; revised Sept. 10, 2007; accepted Sept. 10, 2007.

This work was supported by United States Public Health Service Grants R01 DA16898, K05 DA20570 (C.C.), F32 DA020430 (M.R.B.), and T32 DA07278 (B.B.L.). We thank Drs. Marc Caron and Robert J. Lefkowitz for GRK3 knock-out mice (GRK3 $-/-$ ) and Dr. John Pintar for $\kappa$-receptor knock-out mice (KOR-/-). We thank Dan Messenger for mouse genotyping and assistance with mouse cannulations.

Correspondence should be addressed to Dr. Charles Chavkin, Department of Pharmacology, Box 357280, University of Washington School of Medicine, Seattle, WA 98195-7280. E-mail: cchavkin@u.washington.edu. DOI:10.1523/JNEUROSCI.3769-07.2007

Copyright $\odot 2007$ Society for Neuroscience 0270-6474/07/2711614-10\$15.00/0 phin released during chronic stress exposure produces immobility in the Porsolt forced swim test (Mague et al., 2003; McLaughlin et al., 2003a), social defeat behaviors in the Miczek assay (McLaughlin et al., 2006), and potentiation of the rewarding effects of cocaine in the conditioned place preference (CPP) assay (McLaughlin et al., 2003a). These results suggest that dynorphin activation of the $\kappa$-opioid receptor (KOR) may encode the dysphoric component of stress (Kreek and Koob, 1998).

The $\kappa$-opioid system is comprised of the prodynorphin peptide products and the KOR, a seven membrane spanning, $\mathrm{G}_{\mathrm{i} / \mathrm{o}^{-}}$ protein-coupled receptor (GPCR) (Akil et al., 1984). $\kappa$-Opioid receptors are widely distributed in the brain, including expression in several brain structures thought to be critical for behavioral responses to drugs of abuse, depression, and learning and memory (Mansour et al., 1987). In addition to the regulatory effects on adenylate cyclase and ion channel conductance typical of $\mathrm{G}_{\mathrm{i} / \mathrm{o}}$-coupled receptors, sustained activation of $\kappa$-opioid receptors leads to the activation mitogen-activated protein kinase pathway (MAPK) in heterologous systems and native cells (Belsheva et al., 2005; Bruchas et al., 2006). Using in vitro assays, $\kappa$ agonists have been shown to activate all three MAPK family members, including the extracellular signal-regulated kinase (ERK), the stress kinase c-Jun N-terminal kinase (JNK), and the stress kinase p38 in transfected cells and primary cultured astrocytes and neurons (Kam et al., 2004; Belsheva et al., 2005; Bruchas 
et al., 2006). However, KOR-mediated MAPK activation in vivo has not yet been demonstrated, and a possible relationship between p38 MAPK activation and $\kappa$-induced behaviors has not been established.

We used the modified Porsolt repeated forced swim-stress paradigm previously demonstrated to induce dynorphin release and subsequent activation of KOR in mice (Mague et al., 2003; McLaughlin et al., 2003a). KOR activation of a MAPK pathway is one possible mechanism for the long-lasting effects of repeated stress, and in the present study, we directly assessed the role of p38 MAPK activation in mediating these behavioral responses to KOR activation. We found that inhibition of p38 MAPK blocked the dynorphin-mediated enhancement of swim stress-induced immobility and blocked the conditioned place aversion induced by $\kappa$ agonist administration.

\section{Materials and Methods}

Drugs and chemicals. Nor-binaltorphimine (norBNI)-HCl and (士)U50488 were obtained from Tocris Bioscience (Ellisville, MO). SB203580 [4-(4-fluorophenyl)-2-(4-methylsulfonylphenyl)-5-(4pyridyl)- $1 \mathrm{H}$-imidazole]-HCl was obtained from Calbiochem (La Jolla, $\mathrm{CA}$ ). Cocaine- $\mathrm{HCl}$ was obtained from the National Institute of Drug Abuse (Rockville, MD). Drugs were dissolved in $0.9 \%$ saline, unless otherwise indicated.

Animals and housing. Male C57BL/6 mice (Charles River Laboratories, Wilmington, MA) weighing 22-30 g were used in these experiments as described previously (McLaughlin et al., 2003a). Animal procedures were approved by the Institutional Animal Care and Use Committee in accordance with the 1996 National Institutes of Health Guide for the Care and Use of Laboratory Animals, and mice were regularly inspected by University of Washington veterinary staff to ensure compliance.

Breeding and genotyping of knock-out mice. Homozygous $\operatorname{KOR}(-/-)$ mice were prepared by homologous recombination as described previously (Clarke et al., 2002) and provided for this study. G-protein receptor kinase (GRK) 3(-I-) mice were generated as described previously (Peppel et al., 1997). Animals were backcrossed for $>10$ generations with $\mathrm{C} 57 \mathrm{BL} / 6$ mice, and heterozygote breeding pairs were used to generate homozygotic knock-out mice of each type and paired wild-type (WT) littermate controls and genotyped as described previously (Bruchas et al., 2006; McLaughlin et al., 2006).

Cannulation and intracerebroventricular injections. Isoflurane anesthetized mice were mounted on a stereotaxic alignment system (David Kopf Instruments, Tujunga, CA), guide cannulas (26 gauge, $2.4 \mathrm{~mm}$ from pedestal; Plastics One, Roanoke, VA) were placed in the lateral ventricle at $1.0 \mathrm{~mm}$ lateral, $0.4 \mathrm{~mm}$ posterior from bregma, and $3 \mathrm{~mm}$ below the skull, as described previously (Rahmouni et al., 2003; Paxinos and Franklin, 2004). Guide cannulas were anchored with screws (CMA/Microdialysis, Stockholm, Sweden) using dental cement, and dummy internal cannulas were placed inside until injection. After surgery, mice recovered in their home cage for 6-8 d. Mice were injected intracerebroventricularly by placing a 33 gauge internal cannula (Plastics One) into the guide cannula attached to a flared PE20 tube connected to a $10 \mu$ l Hamilton syringe. Injection volumes $[1 \mu \mathrm{l}$ for forced swim stress (FSS), and $4 \mu \mathrm{l}$ for conditioned place aversion (CPA), same concentration] of saline or SB203580 were performed during a 2 min period. Internal cannulae were removed $\sim 1 \mathrm{~min}$ after injection. After intracerebroventricular injection, mice returned to their home cage for $30 \mathrm{~min}$ before testing for both CPA and FSS studies. For FSS studies, mice were injected again with $1 \mu \mathrm{l}$ of $(0.5 \mathrm{nmol}$ ) SB203580 after swim 2, and swim 3 on day 2 (see below for detail on FSS procedure).

FSS and stress-induced immobility. C57BL/6 mice were exposed to a modified Porsolt forced swim stress (Porsolt et al., 1977) as described previously (McLaughlin et al., 2003a). Briefly, mice were placed for 15 min on day 1 in a $5 \mathrm{~L}$ beaker $(40 \mathrm{~cm}$ tall $\times 25 \mathrm{~cm}$ in diameter) filled with $3.5 \mathrm{~L}$ of $30 \pm 1{ }^{\circ} \mathrm{C}$ water. On day 2 , animals were placed in water to swim through a series of four trials, each 6 min long; trials were separated by a $6 \mathrm{~min}$ return to home cage. Time spent immobile in the last $5 \mathrm{~min}$ of each trial was recorded using a Canon ZR90 camcorder. In this paradigm, repeated inescapable swim results in a progressive increase in the amount of time the animal remains immobile, defined by stationary posture, motionless forelimbs directed forward, outward extended tail, and limited motion of the hindlimbs. Experiments were performed and analyzed with the investigator blind to the treatment. Videos were imported into Noldus Ethovision (version 3.0; Noldus Information Technology, Wageningen, The Netherlands) software for analysis of time spent immobile and distance traveled. Saline or SB203580 HCl were injected intracerebroventricularly $30 \mathrm{~min}$ before swim-stress trials on both day 1 and day 2.

Locomotor activity was evaluated in a test chamber $(28 \mathrm{~cm}$ length $\times 16$ $\mathrm{cm}$ width $\times 13 \mathrm{~cm}$ height) using video tracking and motion analysis, performed via the Noldus Ethovision program (as above). The camera was placed $3 \mathrm{~m}$ above the chamber and collected five samples per second for each test. To evaluate the effects of SB203580 on locomotor behavior, mice were placed in the test chamber for a $60 \mathrm{~min}$ environmenthabituation period, injected with SB203580 ( $0.5 \mathrm{nmol})$ or saline, placed back into the test chamber, and locomotor activity was recorded during the after $60 \mathrm{~min}$.

Conditioned taste aversion. Conditioned taste aversion assay was performed as described previously (Koh et al., 2003). Lateral ventrical cannulated mice were individually housed and allowed to acclimate for 2-3 d. After this period, water intake was restricted to $0.5 \mathrm{~h}$ in the morning and $1.5 \mathrm{~h}$ in the afternoon for three consecutive days to promote drinking during the conditioning and test days. The mouse weights and water intakes were monitored during this time to ensure the animals were not dehydrated. Animals were then divided into groups based on preconditioning water intake and body weight to avoid systematic differences. On conditioning day, animals were injected with either SB203580 (p38 inhibitor, $0.5 \mathrm{nmol} / \mathrm{ml})$ or saline $(1 \mu \mathrm{l})$ in the morning. Fifteen minutes after intracerebroventricular injection, animals were given access to the tastant $(0.5 \%$ saccharin $)$ for $15 \mathrm{~min}$. Immediately after taste presentation, animals were injected with lithium chloride $(\mathrm{LiCl}, 0.15 \mathrm{M}, 10 \mathrm{ml} / \mathrm{kg}$, i.p.) or saline $(0.15 \mathrm{M}, 10 \mathrm{ml} / \mathrm{kg}$, i.p.). This dose of $\mathrm{LiCl}$ is sufficient to produce malaise. In the afternoon of the conditioning day, animals received water as they did during deprivation and were restricted again overnight. On test day, animals were presented with one bottle containing $0.5 \%$ saccharin and the other bottle containing water. The amount consumed from each bottle during the next 30 min was recorded, and a preference score was calculated as the fraction of saccharin solution consumed.

Immunohistochemistry. Immunohistochemistry was performed as described previously (Xu et al., 2004, 2007). Mice were anesthetized with pentobarbital (Sigma, St. Louis, MO) and intracardially perfused with $4 \%$ para-formaldehyde in phosphate buffer ( $\mathrm{PB}$ ) (0.1 M sodium phosphate, $\mathrm{pH}$ 7.4). Brains were dissected, postfixed for $2 \mathrm{~h}$ in the same fixation buffer, cryoprotected with solution of $30 \%(\mathrm{w} / \mathrm{v})$ sucrose in $\mathrm{PB}$ at $4^{\circ} \mathrm{C}$ overnight, cut into $30 \mu \mathrm{m}$ sections, and processed for immunostaining. Sections were washed three times in PBS and blocked in PBS containing $0.3 \%$ Triton X-100 and 5\% normal goat or donkey sera. Sections were then incubated with a mixture of mouse anti-glutamic acid decarboxylase 67 (GAD67) (Chemicon, Temecula, CA) and rabbit phosphop38 monoclonal antibody (1:100; Cell Signaling Technology, Beverly, MA) or rabbit anti-Egr-1 (zif268) (1:400; Cell Signaling Technology), or rabbit anti-pCREB (1:100; Cell Signaling Technology), or mouse phospho-p38 monoclonal antibody (1:50; Santa Cruz Biotechnology, Santa Cruz, CA), or rabbit antiphospho-KOR Ab [15-30 $\mu$ g total/section depending on antibody preparation as described previously (McLaughlin et al., 2004; Xu et al., 2007)]. Sections were then washed with PBS, and detection was performed using the fluorescent secondary antibody FITC goat anti-mouse IgG (1:250; Jackson ImmunoResearch, West Grove, PA) and Cy3 donkey anti-rabbit IgG (1:500; Jackson ImmunoResearch). Antibodies were diluted in a solution with $0.3 \%$ Triton X-100 in PBS. Sections were rinsed in PBS for $30 \mathrm{~min}$ and mounted on gelatin-coated slides with Vectashield containing 4',6'-diamidino-2-phenylindole (DAPI) nuclear stain (Vector Laboratories, Burlingame, CA) and sealed with nail polish. Sections were viewed with a Nikon Eclipse E600 fluorescence microscope (Tokyo, Japan) or a Leica confocal microscope located in the 
W. M. Keck Center for Advanced Neural Imaging at the University of Washington. For the cell count experiments, P-p38-positive and GADpositive cells were taken from four to five separate images (fields of $\sim 200 \mu \mathrm{m}^{2}$ ) that were assigned letters, mixed, and counted blindly with a cell designated positive if the P-p38 or GAD staining was at least $100 \%$ over background, as determined by optical density using MetaMorph (Downingtown, PA).

Isolation and immunoblotting of mouse brain striatal proteins. Mice were decapitated at specified times, striata were dissected, and homogenized using a dounce tissue homogenizer for 30-60 s on ice in buffer containing $50 \mathrm{~mm}$ Tris- $\mathrm{HCl}, 300 \mathrm{~mm} \mathrm{NaCl}, 1 \mathrm{~mm}$ EDTA, $1 \mathrm{~mm}$ Na3VO4, $1 \mathrm{~mm} \mathrm{NaF,} \mathrm{10 \%} \mathrm{Glycerol,}$ 1:100 Phosphatase Inhibitor Cocktail Set 1 (Calbiochem), and then sonnicated for $20 \mathrm{~s}$. Protein was separated by PAGE and transferred to nitrocellulose as described previously (Bruchas et al., 2006). Blots were blocked in 5\% BSA (for p38, pERK, and pCREB Western blots) or 5\% milk (Egr-1) in Tris-buffered saline, for $1 \mathrm{~h}$ at room temperature. Blots were then incubated overnight at $4^{\circ} \mathrm{C}$ with a primary goat anti-rabbit antibody recognizing phospho-p38 MAPK, pCREB, pERK, or zif268 (Cell Signaling Technology) at a dilution of 1:1000. Blots were also coincubated with goat anti-mouse $\beta$-actin at a dilution of 1:1000. (AbCam, Cambridge, MA) for confirmation of equal protein loading. Blots were then washed four to five times for $10 \mathrm{~min}$ in Tris-buffered saline containing $0.1 \%$ Tween-20. After wash, blots were incubated for $1 \mathrm{~h}$ with IR-Dye 800-conjugated goat anti-rabbit IgG secondary antibody diluted at $1: 10,000$ in $2.5 \%$ milk/ $100 \%$-Li-COR blocking buffer (Li-COR, Lincoln, NE); for $\beta$-actin double labeling, IR-Dye-680conjugated goat anti-mouse IgG secondary antibody was diluted at $1: 10,0002.5 \%$ milk/ $100 \%$-Li-COR blocking buffer with the above. Antibody labeling was then visualized using the Odyssey Imaging system ( $\mathrm{Li}-\mathrm{COR}$ ), and fluorescence intensity was quantified.

$C P A$. Lateral ventricle cannulated wild-type mice were used in a balanced three-compartment conditioning chamber as described previously (McLaughlin et al., 2003a; McLaughlin et al., 2006). Mice were initially pretested for place preference by placing individual animals in the small central compartment and allowing them to freely explore the entire apparatus for $30 \mathrm{~min}$. Movement through each chamber (different stripes of horizontal or vertical design, and different bedding in each) was recorded using video capture from above and measured using Noldus Ethovision software (version 3.0). The apparatus was balanced, and mice were then randomly assigned their drug and saline training compartments for the training sessions (30 min). Mice received saline ( $100 \mathrm{ul} / 10 \mathrm{~g}$ of body weight, i.p.) in the morning and either saline, U50488 (2.5 mg/kg, i.p.), or cocaine ( $15 \mathrm{mg} / \mathrm{kg}$, s.c.) in the afternoon on days 2 and 3. For mice that were treated with the p38 inhibitor SB203580 ( $0.5 \mathrm{nmol}$, i.c.v.), the drug (or saline control) was injected 30 min before the U50488 or cocaine injection. Conditioned preference was assessed on day 4 by allowing the mice to roam freely in all three compartments and recording the time spent in each. CPA and CPP scores were calculated by the time spent in the drug-compartment posttest minus the pretest and plotted using Graph Pad Prism 4.0 (San Diego, CA).

8
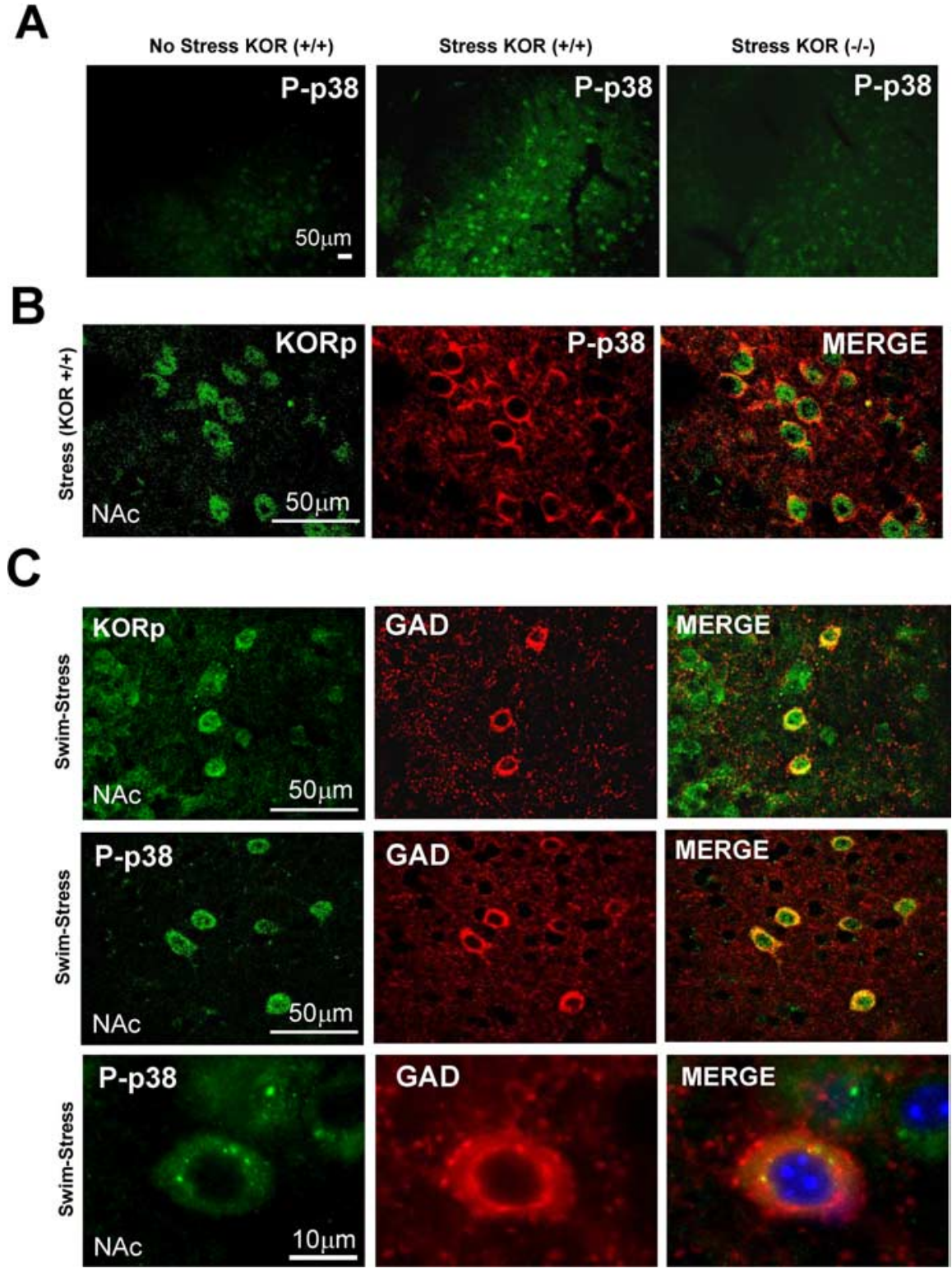

Figure 1. Repeated swim-stress results in KOR-dependent P-p38 staining on GABAergic cells in the nucleus accumbens. $A_{\text {, }}$ Representative images of phospho-p38 (P-p38; green) in NAc after repeated swim-stress exposure, in stressed or nonstressed KOR wild-type $(K O R+/+)$ and stressed knock-out mice (KOR $-/-)$. B, Representative images of phospho-p38 (P-p38; green) and Representative images of NAc phospho-KOR (KORp; green) and GAD (red) staining after repeated swim-stress exposure. Middle row, Higher magnification of phospho-p38 (green) costaining with the GABA marker (GAD; red) in NAc after repeated swim-stress exposure, in wild-type mice. Bottom row, Show representative high-magnification image of colabeled phospho-p38 (green) staining, GAD (red), and nuclear stain, DAPI (blue). All images are representative of three to four independent experiments.

Data analysis. Western blot signal intensity was quantified using the Odyssey imaging software (version 1.2) (Li-COR) as described previously (Bruchas et al., 2006). Data were normalized to control (noswim) values for all groups. Student's $t$ test was used to determine statistical differences between pair-wise comparisons. Behavioral data were collected using the Noldus Ethovision software (version 3.0) and were analyzed using repeated measures ANOVA (one- or two-way as appropriate). Significant results demonstrated by oneway ANOVA were further analyzed by a post hoc Bonferroni's multiple comparison test. For conditioned place aversion and conditioned taste aversion, one-way ANOVA to determine differences between groups, followed by $t$ tests between for each paired group of interest was performed. All data are presented as means \pm SEM of the animal group, with significance set at $p<0.05$. 
A
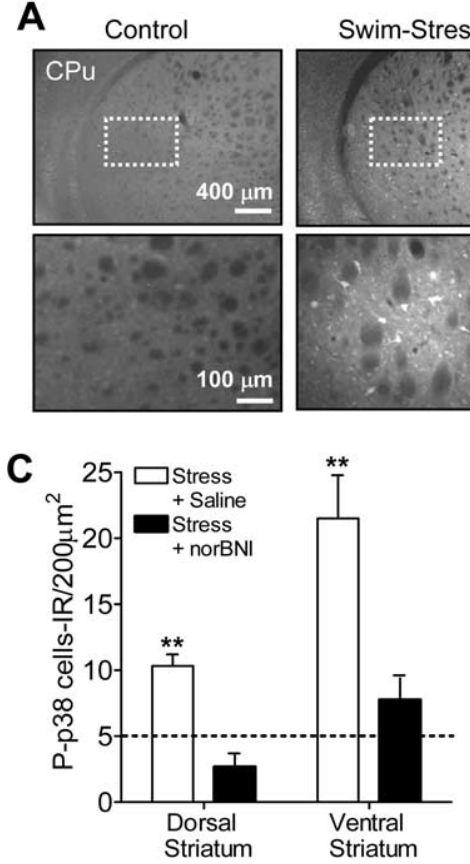

B

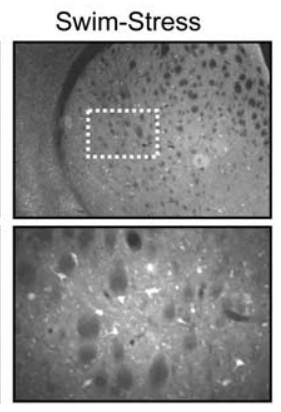

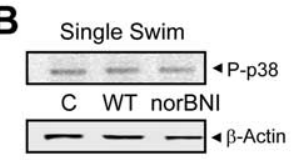

KOR (-/-) Repeated Swim

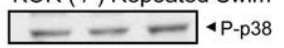

C $10 \quad 30 \mathrm{~min}$ $--(-$-Actin

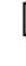

WT-Repeated Swim

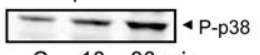

C $10 \quad 30 \mathrm{~min}$

$\sim-$ A-Actin

NorBNI Repeated Swim 4 P-p38

$\longrightarrow$-Actin
C $10 \quad 30 \mathrm{~min}$

Using the KOR-P antibody to image sites of dynorphin action, we found that repeated swim stress also increased KORp-IR in NAc (Fig. $1 B$ ) and cortex (supplemental Fig. 2C, available at www.jneurosci.org as supplemental material). Previous studies showed that an increase in KORp-IR was only evident in wild-type but not in $\operatorname{KOR}(-/-)$ mice, mice pretreated with norBNI, or mice lacking prodynorphin-derived opioids (Dyn-/-) (McLaughlin et al., 2004). Double-labeling for KORp-IR and P-p38-IR in sections of NAc showed that KOR activation and p38 activation occur in the same cells (Fig. 1B). Colocalization was further suggested by the detection of both KORp-IR and P-p38-IR in GAD-IR neurons in NAc (Fig. 1C). These in vivo results are consistent with previous in vitro studies showing that P-p38-IR was selectively increased in KOR-expressing primary neurons isolated from mouse striatum (Bruchas et al., 2006). The selective dependence of $\mathrm{p} 38$ activation on KOR was not expected.

To quantify the increase in P-p38-IR and validate the immunohistochemical findings, extracts of whole striatum were resolved by Western blot analysis (Fig. 2). Whole striatum was used to provide sufficient brain tissue for the less-sensitive immunoblot method. Repeated swim stress increased P-p38-IR in the caudateputamen ( $\mathrm{CPu}$; dorsal striatum) (Fig. $2 A)$. In contrast, $\mathrm{P}-\mathrm{p} 38$-IR did not significantly increase in mice pretreated with norBNI

\section{Results}

Repeated swim stress causes KOR-mediated activation of p38 MAPK

Mice subjected to repeated swim stress showed activation of both KOR and p38 MAPK in the nucleus accumbens (NAc), cortex, and hippocampus. Sites of activation were visualized using the phosphoselective antibodies against activated $\kappa$ receptors (KOR-P) (McLaughlin et al., 2003b; McLaughlin et al., 2004) and phosphoselective antibodies against p38. Repeated swim stress (five swim episodes over $2 \mathrm{~d}$ ) caused a robust increase in phospho-p38 immunoreactivity in wild-type C57BL/6 mice as evident from images of NAc $0-30 \mathrm{~min}$ after the final swim (Fig. $1 A)$. Surprisingly, $\mathrm{P}$-p38-IR did not increase in $\operatorname{KOR}(-/-)$ littermates subjected to the same swim paradigm (Fig. 1A). The increase in P-p38-IR evident NAc after repeated swim stress was also blocked by pretreatment with the KOR antagonist norBNI (supplemental Fig. 1, available at www.jneurosci.org as supplemental material). High-resolution imaging showed that a large portion of the P-p38-IR after stress was cytosolic (Fig. 1C). Repeated swim stress also increased P-p38-IR in hippocampal and cortical neurons (supplemental Fig. $2 A-C$, available at www. jneurosci.org as supplemental material). In each region, the P-p38-IR increased in GABAergic neurons shown by GAD67 (GAD-IR) double labeling. These results show that forced swim stress increased p38 phosphorylation in GABAergic neurons in hippocampus, cortex, and NAc. or in $\operatorname{KOR}(-/-)$ mice after repeated swim stress (Fig. $2 B$ ). Interestingly, wild-type mice exposed to only a single $15 \mathrm{~min}$ swimstress episode did not increase P-p38-IR in striatum (Fig. 2 B). When quantifying the change in P-p38-IR in tissue sections after repeated swim stress, we found that the norBNI-sensitive increase occurred in both dorsal and ventral striatum (Fig. 2C). Western analysis showed that P-p38-IR was nearly doubled for 60 min after the last swim episode in wild-type mice but did not significantly increase in norBNI pretreated or $\operatorname{KOR}(-/-)$ mice (Fig. 2D). The intensity of P-p38-IR returned to baseline levels $6 \mathrm{~h}$ after the last swim for wild-type mice. These immunoblot results provide additional evidence that repeated swim stress induced KOR-dependent activation of p38 MAPK in the mouse brain.

\section{Inhibition of p38 MAPK attenuates swim} stress-induced immobility

The relationship between p38 activation and the behavioral effects of $\kappa$ receptor activation was next explored. The effects of the water-soluble, selective p38 inhibitor SB203580 (Gallagher et al., 1997; Young et al., 1997; Bhat et al., 1998; Xu et al., 2007), administered by intracerebroventricular injection were assessed in the repeated swim protocol (Fig. 3A). Pretreatment with $0.5 \mathrm{nmol}$ of SB203580 had no significant effect on time immobile during the first swim session (Fig. 3A, swim 1). However, during the second and third swims on day 2 (swim 3 and swim 4), swim stress- 
A

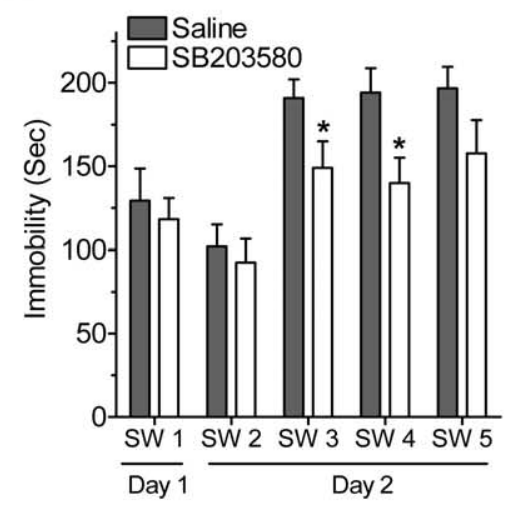

B

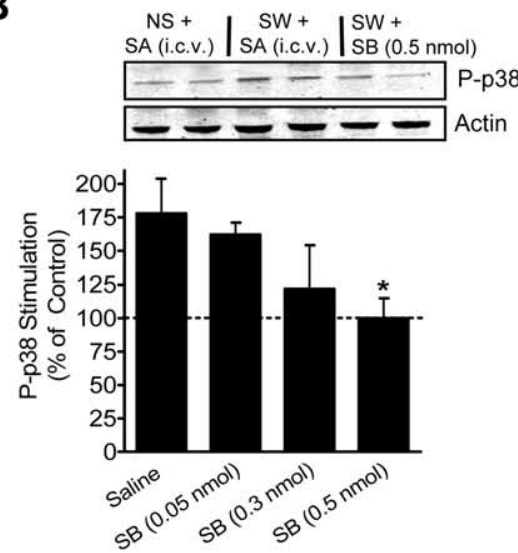

C

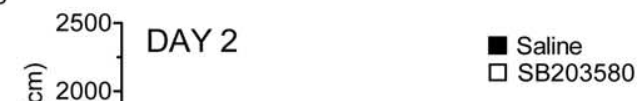

Figure 3. Inhibition of 38 MAPK attenuates swim stress-induced immobility. $\boldsymbol{A}$, Time spent immobile during the last 5 min of the forced swim stress measured during multiple trials over $2 \mathrm{~d}$ after intracerebroventricular injection ( $30 \mathrm{~min}$ before swim) of saline or $0.5 \mathrm{nmol} / \mathrm{mouse}$ of SB203580. Mice were injected a second and third time with $0.5 \mathrm{nmol} / \mathrm{mouse}$ between swims (SW) 1 and 2 and 2 and 3. As expected, SB203580 had no significant effect on time spent immobile on the first day of testing (swim 1; black bar). However, on the second day of forced swim, inhibition of p38 MAPK with SB203580 caused a significant decrease in time spent immobile on the second and third exposures (swim 3 and swim 4; $n=19-21$, with each $n$ taken as a separate animal; * $p<0.05$, as determined by ANOVA followed by the Bonferroni's post hoc test). B, To confirm lowered P-p38 activity in SB203580-treated mice, we measure the SB203580 effect on P-p38 in mouse striatum as determined by Western blot analysis. Top, Representative Western blot of P-p38 after swim stress and SB203580 treatment. Lanes are as follows: no swim plus saline group (NS + SA), swim plus saline (SW + SA), and swim plus SB0203580 (0.5 nmol/mouse). Each lane was taken from one striatum of one animal. $\beta$-Actin staining was used to confirm equal protein loading. Bottom, Bar graph data are the mean \pm SEM of P-p38 compared with control (No Swim + Saline group) for each of the treatments designated below the graph. The dashed line denotes basal (control; $n=4-8$, with each $n$ taken as a separate animal; ${ }^{*} p<0.05$, compared with control, saline-injected mice; $t$ test). $C$, Data are the means \pm SEM of mouse locomotor activity (distance traveled in centimeters vs time in minutes) before and after intracerebroventricular injection of $0.5 \mathrm{nmol}$ of SB203580 or saline. Mice were injected $1 \mathrm{~h}$ after initial exposure to locomotor chamber as indicated.

induced immobility was decreased in mice pretreated with SB203580 ( $0.5 \mathrm{nmol})$; this decreased immobility was significantly different from saline-injected mice (Fig. 3A, swim 3, swim 4) $\left(F_{(7,}\right.$ ${ }_{117)}=8.66 ; p<0.0001$ for one-way ANOVA; $n=19-21 ; p<$ 0.05 , Bonferroni's post hoc comparing saline Swim 3 vs SB203580 swim 3 and saline swim 4 vs SB203580 swim 4). The effect of SB203580 was not as clear on swim 5, which may be attributed to the pharmacokinetics of the drug or compensatory effects by other immobility mediators. Consistent with the immobility results, pretreatment with SB203580 $(0.5 \mathrm{nmol})$ also effectively reduced the increase in P-p38-IR in striatum after repeated swim stress (Fig. 3B). We did not detect any change in phospho-ERK or phospho-JNK after SB203580 administration (data not shown), further supporting the presumed selectivity of this compound. The effects of SB203580 only during the second day is consistent with previously reported effects of $\kappa$ antagonism (Pliakas et al., 2001; McLaughlin et al., 2003a).

We then assessed whether blockade of p38 signaling would also affect other behavioral responses. Nonselective effects of SB203580 on locomotor activity under these conditions were not observed; no significant difference in locomotor activity between the saline and SB203580 groups was evident on either day $1\left(F_{(23)}\right.$ $=0.44$ for interaction; $p>0.05$, two-way ANOVA) (data not shown) or day $2\left(F_{(23)}=0.39\right.$ for interaction; $p>0.05$, two-way ANOVA) (Fig. $3 C$ ). These data suggest that the reduction in swim stress-induced immobility, characteristic of antidepressant drugs, was not attributable to an increase in mouse locomotor behavior caused by p38 inhibition. Selectivity was further assessed by measuring the effects of SB203580 on stress-induced analgesia previously shown to be KOR mediated (McLaughlin et al., 2003a). Swim stress caused a significant increase $(p<$ $0.01)$ in tail-flick latency from basal $(2.1 \pm 0.26 \mathrm{~s})$ to poststress $(4.3 \pm 0.87 \mathrm{~s})$, and this increase was not blocked by SB203580 (supplemental Fig. 3, available at www.jneurosci.org as supplemental material). These results suggest that SB203580 did not block the stress-induced release of dynorphin or block the analgesic effects of KOR activation. The selectivity of
SB203580 observed suggests that KOR-mediated swim stressinduced immobility required p38 MAPK activation.

\section{$\kappa$ Agonist-induced CPA is mediated by p38 MAPK activation}

KOR activation also causes CPA (Spanagel et al., 1994; Sante et al., 2000; Contarino and Papaleo, 2005). We next asked whether KOR-induced CPA requires p38 MAPK activity. Mice were conditioned with the KOR agonist U50488 $(2.5 \mathrm{mg} / \mathrm{kg})$ in one chamber of a balanced place preference apparatus and saline in the other. The subsequent reduction in time spent in the drug-paired chamber was scored as aversion, and the training paradigm is outlined in Figure 4A. Consistent with previous studies, U50488 conditioning caused robust place aversion (Fig. $4 B$ ). Pretreatment with SB203580 ( $0.5 \mathrm{nmol}$, i.c.v.) $30 \mathrm{~min}$ before injection of U50488 significantly blocked the CPA ( $p<0.05, t$ test U50488/ saline vs U50488/SB203580) produced by KOR activation (Fig. $4 B$ ). Mice given saline in both chambers showed no preference, and mice pretreated with SB203580 alone in the absence of U50488 also showed no place preference (Fig. 4 B). These results confirm that the chambers were balanced and that SB203580 alone was not producing an opposing place preference.

To assess whether p38 inhibition blocked KOR-induced CPA by disrupting associative learning, we tested whether p38 inhibition blocked cocaine conditioned place preference under the same conditions. In this assay, mice learn an association between neutral cues (flooring texture and smell and chamber wall striping) and the positive stimuli caused by cocaine. Interestingly, pretreatment with SB203580 had no effect on cocaine $(15 \mathrm{mg} / \mathrm{kg}$, s.c.) conditioned place preference (Fig. $4 B$ ). We also used a conditioned taste aversion model to test for nonselective learning effects of SB203580 in a different, associative aversion paradigm that is not affected by KOR gene deletion (data not shown). In this protocol, mice learn to avoid drinking a saccharin solution if they received a paired $\mathrm{LiCl}$ injection. Preinjection of SB203580 before the saccharin-LiCl pairing did not significantly affect the subsequent taste aversion scores, indicating that SB203580 does 


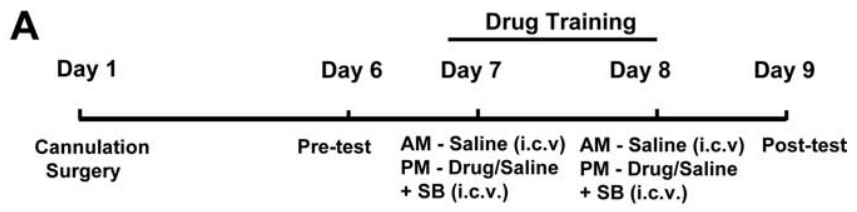

B
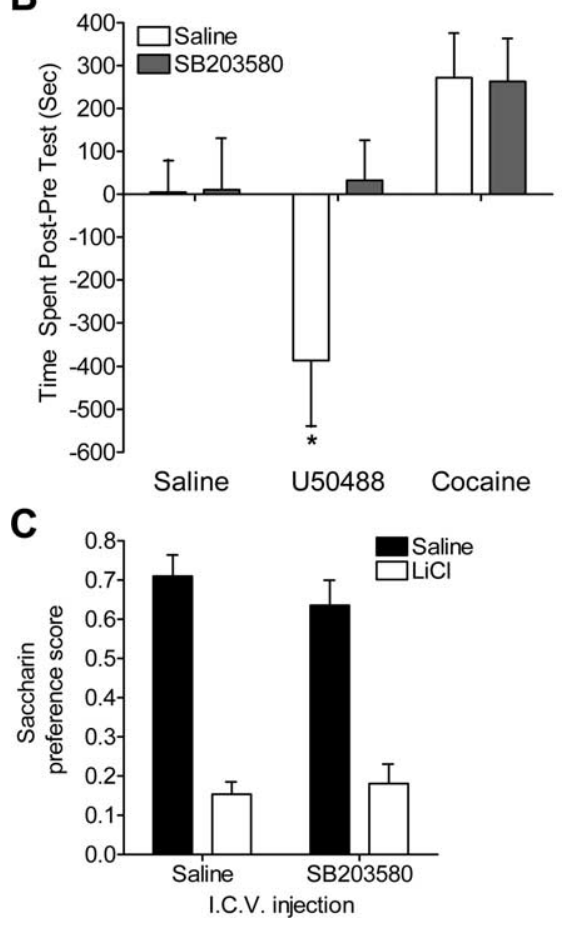

Figure 4. U50488-mediated (PA, but not cocaine CPP, is mediated by p38 MAPK (A). Timeline for CPA studies: mice were pretested on day 1, trained with drug [U50488 (2.5 mg/kg, i.p.), saline (i.p.), or cocaine $(15 \mathrm{mg} / \mathrm{kg})]$ on days 2 and 3 , and posttested for preference or aversion on day 4 (see Materials and Methods). B, Mean (PA data: $U 50488$ (2.5 mg/kg, i.p.) caused a significant CPA as measured by time spent posttest minus pretest in the drug-paired side. U50488-mediated CPA was significantly blocked by injection of p38 inhibitor SB203580 (SB) $(0.5 \mathrm{nmol}$, i.c.v., $30 \mathrm{~min}$ before U50488, i.p.) Saline training (i.p.) did not produce (PA in either SB203580 (i.c.v.)-injected group or saline (i.c.v.)-injected groups. Cocaine (PP was unaffected by p38 inhibition; there was no significant difference between saline (i.c.v.)-injected and SB203580-injected place preference scores in cocaine-trained mice. ${ }^{*} p<0.05, t$ test $(n=$ $6-9$ ). C, Data are the means \pm SEM of mouse conditioned taste aversion scores (Saccharin preference score $=$ amount of saccharin consumed/total consumption) after intracerebroventricular injection of $0.5 \mathrm{nmol}$ of SB203580 or saline (see Materials and Methods). There was no difference between SB203580 and saline-treated mice taste aversion scores. $n=6-7$, where each $n$ is a separate animal.

not nonselectively affect general avoidance learning in mice (Fig. $4 C)$. These findings indicate that $\mathrm{p} 38$ activation may be selectively required for the aversive effects of $\kappa$ activation.

\section{KOR-mediated p38 activation, KOR-mediated aversion, and} KOR-mediated swim stress-induced immobility are Gprotein-coupled receptor kinase- 3 dependent

Previous in vitro studies suggest that GPCR activation of MAPK may require $\beta$-arrestin recruitment (Shenoy and Lefkowitz, 2005; Dewire et al., 2007). We recently reported that $\kappa$-opioid activation of p38 MAPK in vitro required phosphorylation of serine-369 in the C-terminal domain of KOR by GRK and subsequent $\beta$-arrestin activation (Bruchas et al., 2006), and we previously found that the GRK3 isoform was uniquely involved in homologous KOR desensitization (McLaughlin et al., 2004). To assess whether similar signaling events link KOR activation to p38 phosphorylation in brain after behavioral stress, we investigated the role of GRK3 in these processes. First, we performed Western blots on striatal samples taken from GRK3 $(+/+)$ and GRK3(-/-) mice injected with the KOR agonist U50488. Consistent with the KOR-dependent effects of repeated swim stress, activation of KOR by U50488 significantly increased p38 phosphorylation $(p<0.05)$ in mouse striatum (Fig. $5 A, C)$. U50488 stimulation of P-p38 was blocked by pretreatment with norBNI $(10 \mathrm{mg} / \mathrm{kg})$ (supplemental Fig. $1 B$, available at www.jneurosci. org as supplemental material). Furthermore, U50488 treatment of GRK3(-/-) mice did not significantly increase P-p38 (Fig. $5 A, C)$. The effects of GRK3 deletion on P-p38 were selective; U50488 caused a robust increase (approximately twofold) in ERK1/2 phosphorylation in mouse striatum in both wild-type and GRK3(-l-) mice (Fig. 5B,C). The selective inhibition of p38 phosphorylation was consistent with previous in vitro studies showing that KOR-mediated ERK1/2 phosphorylation is GRK3 independent (Bruchas et al., 2006). These results show that KORmediated p38 activation was also GRK3/arrestin dependent in mouse brain.

The in vivo activation of $\mathrm{p} 38$ by KOR in a GRK3-dependent manner suggested that KOR-mediated CPA might also be sensitive to GRK3 gene deletion. Consistent with this prediction, U50488 $(2.5 \mathrm{mg} / \mathrm{kg})$ produced a place aversion in GRK3 $(+/+)$ mice $(-176 \pm 71 \mathrm{~s})$. In contrast, U50488-induced CPA was significantly attenuated in GRK $(-/-)$ mice $(35 \pm 65 \mathrm{~s} ; n=6-8 ; t$ test, $p<0.05)$. We also found that swim stress-induced immobility was significantly decreased in GRK3 $(-/-)$ mice [one-way ANOVA; $F_{(6.48,53)}, p<0.0001$; Bonferroni's post hoc comparing GRK3 $(+/+)$ vs GRK $(-/-) ;{ }^{\star} p<0.05$ or ${ }^{\star *} p=0.01$ ] (Fig. $\left.5 D\right)$. These results support the hypothesis that both stress-induced aversion and stress-induced immobility responses may be mediated by a cascade of events initiated by dynorphin release, KORactivation, GRK3-dependent $\beta$-arrestin recruitment and subsequent p38 activation. Although plausible, this model requires additional validation. In particular, it is not clear how p38 activation results in aversion or immobility. A step toward that understanding requires that we identify the downstream mediators of P-p38 and define the functional consequences of p38 activation.

\section{Repeated stress induces transcription factor upregulation that is p38 MAPK dependent}

Because the p38 MAPK pathway has been shown previously to activate early-phase transcription factors (Hebert et al., 2005) and the downstream effects of stress on neuronal plasticity and behavior are widely considered to be dependent on transcription factor activity (Barrot et al., 2002), we measured the effects of repeated swim-stress exposure on the downstream MAPK effectors, zif268 (Egr-1) and cAMP response element binding protein (CREB). Multiple swim-stress exposure caused a significant upregulation of zif268 protein expression in striatal cell lysates (Fig. $6 \mathrm{~A}$ ) that was not evident in striatal lysates taken from swimstressed $\operatorname{KOR}(-/-)$ mice (Fig. 6A,C). The increase in zif268-IR after swim stress was also evident in tissue sections of the caudateputamen (Fig. $6 \mathrm{~B}$ ). The increased zif268 staining after stress was localized to GAD-positive cells (data not shown), similar to the immunolocalization of phospho-p38 after stress.

Repeated swim-stress exposure also increased phospho-CREB (pCREB) labeling in wild-type but not $\operatorname{KOR}(-/-)$ mice (Fig. $6 \mathrm{~A}, \mathrm{C}$ ). Immunohistochemical results indicated that the increase in pCREB-IR staining was colocalized in GAD-positive cells (data not shown). To assess the role of P-p38 in the KOR-dependent 
activation of CREB and zif268 in striatum after repeated swim stress, we treated mice with SB203580 (0.5 nmol, i.c.v.) before stress exposure and measured zif268 or pCREB by Western blot analysis of striatal extracts (Fig. 6D). SB203580 significantly inhibited the increase in zif268 staining induced by stress ( $p<0.05$; $t$ test). In contrast, SB203580 did not significantly reduce the induction of PCREB caused by repeated swim stress. The lack of effect of p38 inhibition is consistent with reports that CREB activation occurs by other mechanisms, including studies showing that activation of the Ras-MEK-ERK1/2 cascade leads to CREB phosphorylation in vivo (Sindreu et al., 2007). It is noteworthy that SB203580 had a selective inhibitory effect on zif268 but not pCREB induction, and this observation suggests that this immediate early gene (IEG) pathway may be involved in the aversive responses to KOR activation; however, a possible link between zif268 induction and the aversion response has not been established. These data show that stress induces p38 activation that then acts downstream to increase zif268 expression. These data also demonstrate that signal transduction pathway for KOR-mediated p38 activity after stress was distinct from the pCREB signaling cascade.

\section{Discussion}

The principal findings of this study were that repeated swim stress resulted in KORmediated activation of the mitogen activated protein kinase p38 in the mouse NAc, cortex, and hippocampus, and that the inhibition of p38 MAPK activity blocks KOR-mediated stress-induced immobility and conditioned place aversion. These observations are consistent with the hypothesis that endogenous dynorphin released by chronic swim stress induces both immobility and conditioned place aversion that is regulated by KOR-mediated activation of p38 MAPK. Furthermore, this report identifies a novel role for p38 MAPK in selectively regulating aversive behavior.

Previous reports have demonstrated that KOR blockade, KOR gene disruption, and prodynorphin gene disruption prevent forced swim stress-induced increases in immobility, swim stressinduced analgesia, and swim-stress potentiation of cocaine conditioned place preference (Pliakas et al., 2001; Clarke et al., 2002; Mague et al., 2003; McLaughlin et al., 2003a, 2006). Previous studies demonstrated that $\kappa$ receptor activation in striatal primary cultures induces p38 phosphorylation (Bruchas et al., 2006), and this study extends those findings by showing that $\mathrm{p} 38$ MAPK inhibition blocks specific behavioral effects of KOR activation. The in vivo immunohistochemistry studies suggest that p38 may have been activated directly in both KOR-expressing and GAD-positive cells in mouse brain. KOR mediation was suggested by the pharmacological selectivity of U50488, the absence of effects in the KOR - / - mice, and the sensitivity of the effects to the selective $\kappa$ antagonist norBNI shown in this study.

Interpretation of these results depends on assumptions of the
B
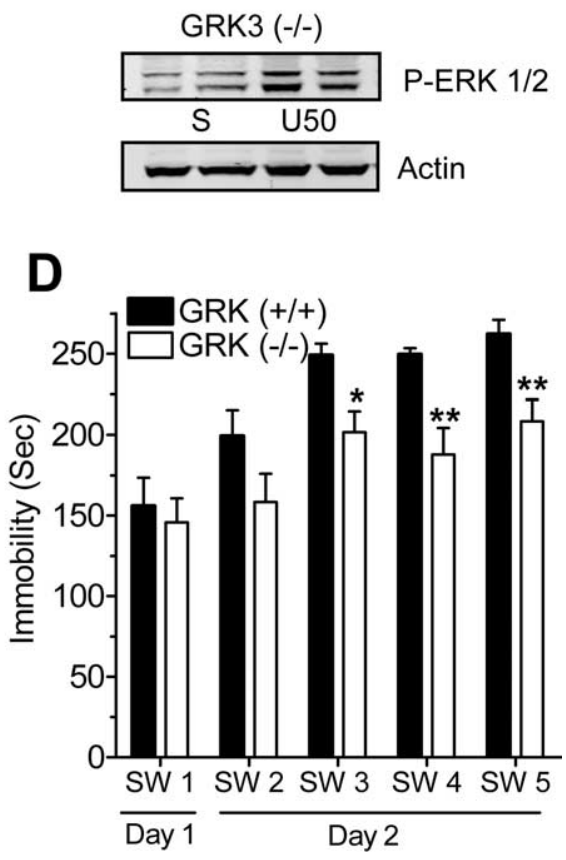

$(-/-)$

$(-/-)$

Day 2

Figure 5. GRK3 is required for KOR-mediated p38 activation, KOR-mediated CPA, and KOR-mediated swim stress-induced immobility. A, Top, Representative Western blots of P-p38 after administration of U50488 (U50) (20 mg/kg, i.p.) (duplicate lanes) 作

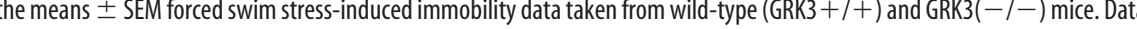
that over swim trials (SW), wild-type mice show a characteristic increase in swim stress-induced immobility; however GRK3 (-I-) mice show a significantly reduced immobility response. ${ }^{*} p<0.05$, ${ }^{* *} p<0.01$, one-way ANOVA followed by

specificity of SB203580. Previous reports demonstrated that SB203580 does not inhibit protein kinase A, protein kinase C, or other mitogen-activated protein kinases including MEK, ERK, or JNK (Gallagher et al., 1997; Young et al., 1997; Bhat et al., 1998; $\mathrm{Xu}$ et al., 2007). Consistent with these reports, in our experiments, we found that SB203580 also acted selectively. We found no adverse effects of SB203580 on locomotor activity, stressinduced analgesia, cocaine CPP, or taste aversion. We also did not detect any change in phospho-ERK or phospho-JNK induction after SB203580 administration. The results suggest that SB203580 selectively inhibited p38 activation under the conditions used in this study.

The activation of p38 observed in the present study required multiple, repeated stress exposure. Shen et al. (2004) previously demonstrated that a single $15 \mathrm{~min}$ swim-stress exposure in rats caused an increase in ERK $1 / 2$, and JNK MAPK pathways but that there was no change in phospho-p38 MAPK levels after single swim-stress exposure. Additionally, it has been reported that an increase in MKK4 and JNK MAPK phosphorylation is evident after a single day, $30 \mathrm{~min}(3 \times 10 \mathrm{~min})$ swim-stress exposure (Shen et al., 2004). Anatomically, we found that the most robust changes in phospho-p38 MAPK, sensitive to KOR-blockade or gene disruption were present in the NAc and cortex compared with other brain regions of interest (supplemental Fig. 2, available at www.jneurosci.org as supplemental material). NAc ex- 
A
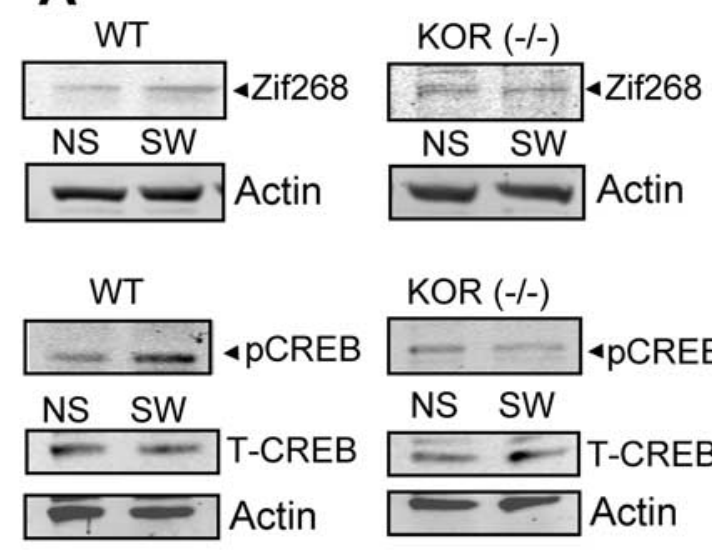

B

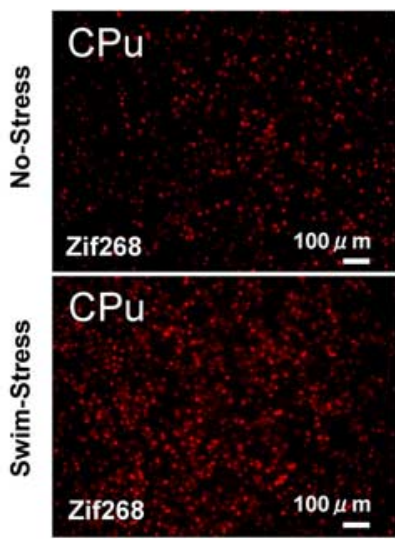

effects supports the concept that chronic activation of the $\kappa$-opioid system by prolonged stress exposure may have a key role in the development of stress-induced depression and may represent the long-term effects of KOR activation.

We found that U50488-induced aversion was blocked by p38 inhibition, suggesting that KOR-mediated p38 activation mediates place aversion. The lack of effect of SB203580 on associative learning in the cocaine CPP assay and taste aversion protocol provided important controls indicating that p38 MAPK inhibition does not nonspecifically inhibit associative learning. These data suggest that p38 MAPK selectively regulates place aversion. A unique role for p38 is particularly surprising given that ERK1/2 MAPK has been demonstrated to be involved in plasticity of brain reward pathways. Recent evidence suggests that the two MAPKs, p38 and ERK1/2, have opposing effects on synaptic plasticity (Bolshakov et al., 2000; Thomas and Huganir, 2004).

Pharmacologic administration of $\kappa$ agonists to humans evokes reports of dysphoria (Vortherms and Roth, 2006), and we presume that the aversion caused by KOR activation in mice was induced by an underlying dysphoric response. One component of this dysphoria is that KOR activation leads to a reduction in dopamine levels in the reward circuit (Spanagel et al., 1994; Shippenberg et al., 2001; Chefer et al., 2005) creating a negative affective state in the animal. It was suggested that the KOR-dependent reduction in dopamine occurs via the action of dynorphin at presynaptic KORs in the striatum. Conversely, in our study, the KOR-dependent p38 activation appears to occur postsynaptically and likely represents the longterm effect of KOR activation after the initial KOR-dependent decreases in pression of KOR-mediated p38 MAPK phosphorylation is consistent with our previous findings of KOR-mediated effects in primary striatal neurons (Bruchas et al., 2006) and is consistent with the role of KOR in the reward circuit of the mouse brain (Spanagel et al., 1994; Shippenberg et al., 2001; Newton et al., 2002). The results show that repeated swim stress activates the dynorphin/KOR p38 cascade in multiple brain regions.

The forced swim-stress assay in rodents is a well-established model for identifying potential antidepressant drugs. Antidepressants consistently reduce the duration of immobility induced by this protocol (Porsolt et al., 1977; Dalvi and Lucki, 1999; Lucki et al., 2001). Reports by Pliakas et al. (2001), Mague et al. (2003), and McLaughlin et al. (2003a) have demonstrated that norBNI blocks swim stress-induced immobility. These findings have prompted strong interest in KOR antagonists as potential antidepressant medications. The antidepressant efficacy of KOR antagonists has not been established in human clinical trials, but our findings that p38 inhibition also produces antidepressant-like

dopamine. Because MAPK activity alters physiology over longer time scales, it is likely that the KOR-dependent p38 MAPK activity after chronic stress and repeated sustained agonist exposure may act to "store" the aversion experience by effects on plasticity as suggested for MAPKs in other models (Thomas and Huganir, 2004); however, this hypothesis requires additional validation.

The role of G-protein-coupled receptor phosphorylation by GRK in signaling has recently gained attention, because it has been shown that sustained agonist occupation and subsequent phosphorylation of the receptor can alter coupling to the MAPK signaling cassette in vitro (Shenoy and Lefkowitz, 2005; Dewire et al., 2007). Our finding that KOR activates p38 MAPK in a GRK3dependent manner in intact brain is consistent with our in vitro studies (Bruchas et al., 2006). Our observation that KOR activates p38 in a GRK3-dependent manner, but that KOR activates ERK1/2 independently of GRK3, provides evidence that these pathways are separate and resolvable (supplemental Fig. 4, available at www.jneurosci.org as supplemental material). 
Understanding the role of p38 activation and subsequent activation of zif268 and CREB transcription factors in the behavioral response requires identification of downstream targets. Changes in gene expression are plausible mechanisms encoding the long-lasting responses to stress. Previous reports document that swim stress increases IEG activation in striatum (Kreibich and Blendy, 2004; Carlezon et al., 2005; Ahmed et al., 2006), and phospho-CREB expression in the nucleus accumbens has been suggested to alter hedonic state (Carlezon et al., 2005). CREB also colocalizes with dynorphin in the NAc and can alter the expression pattern of prodynorphin peptides (Newton et al., 2002). The KOR-dependent activation of the IEG zif268 (also called Egr-1) after stress is consistent with previous studies showing zif268 is a direct downstream target of p38 (Rolli et al., 1999) and suggests that swim stress-induced immobility and aversion could be partly mediated by genes induced by zif268. Recent reports have also demonstrated that zif268 is critical in conditioned withdrawal, another aversive behavioral model (Hellemans et al., 2006). Collectively, these studies suggest that zif268 may be one mediator of the aversive response underlying dysphoria. Although we did not directly establish a connection between KOR-mediated zif268 and aversion, our data showing that zif268 induction was p38dependent suggests that this IEG is at least one downstream target for KOR-mediated p38.

Other substrates of P-p38 that may contribute to the behavioral responses include neuronal membrane proteins. p38 activation regulates the serotonergic system in vitro by reducing both the uptake capacity and cell surface expression of the serotonin transporter (SERT) (Prasad et al., 2005; Samuvel et al., 2005). SERT inhibition has antidepressant effects, and stress-induced inhibition of SERT by a KOR/p38 mechanism is a plausible mechanism. p38 MAPK also contributes to synaptic plasticity by affecting long-term depression mechanisms in vitro (Bolshakov et al., 2000; Thomas et al., 2004) and has been implicated in reflex learning mechanisms (Zhen et al., 2001). In addition, p38 can regulate synaptic targeting of proteins involved in plasticity, including SynGAP, and AMPA receptors (Rumbaugh et al., 2006).

In conclusion, chronic stress induces behavioral changes that can manifest as depression or drug abuse in humans. Understanding the cellular and molecular mechanisms using animal models provides insight and elucidates novel therapeutic targets. Results presented in this study support the hypothesis that stressinduced release of endogenous dynorphins activates KOR/p38dependent events that may underlie the adverse motivational effects of stress. This study highlights the possible relationship between aversive qualities of chronic stress and the $\kappa$-opioid system and suggests an integral role for p38 MAPK in these behavioral responses.

\section{References}

Ahmed T, Frey JU, Korz V (2006) Long-lasting effects of brief acute stress on cellular signaling and hippocampal LTP. J Neurosci 26:3951-3958.

Akil H, Watson SJ, Young E, Lewis ME, Khachaturian H, and Walker JM (1984) Endogenous opioids: biology and function. Annu Rev Neurosci 7:223-255.

Barrot M, Olivier JD, Perrotti LI, DiLeone RJ, Berton O, Eisch AJ, Impey S, Storm DR, Neve RL, Yin JC, Zachariou V, Nestler EJ (2002) Regulation of anxiety and initiation of sexual behavior by CREB in the nucleus accumbens. Proc Natl Acad Sci USA 99:11435-11440.

Beardsley PM, Howard JL, Shelton KL, Carroll FI (2005) Differential effects of the novel kappa opioid receptor antagonist, JDTic, on reinstatement of cocaine-seeking induced by footshock vs cocaine primes and its antidepressant-like effects in rats. Psychopharmacology (Berl) 183:118-126.

Belsheva MM, Clark AI, Haas PD, Serna JS, Hahn JW, Kiss A, Coscia C
(2005) $\mathrm{Mu}$ and kappa opioid receptors activate ERK/MAPK via different protein kinase $\mathrm{C}$ isoforms and secondary messengers in astrocytes. J Biol Chem 280:27662-27669.

Bhat NR, Zhang P, Lee JC, Hogan EL (1998) Extracellular signal-regulated kinase and p38 subgroups of mitogen-activated protein kinases regulate inducible nitric oxide synthase and tumor necrosis factor-a gene expression in endotoxin-stimulated primary glial cultures. J Neurosci 18:1633-1641.

Bolshakov VY, Carboni L, Cobb MH, Siegelbaum SA, Belardetti F (2000) Dual MAP Kinase pathways mediate opposing forms of long-term plasticity at CA3-CA1 synapses. Nat Neurosci 3:1107-1112.

Bruchas MR, Macey TA, Lowe JD, Chavkin C (2006) Kappa opioid receptor activation of p38 MAPK is GRK3-and arrestin-dependent in neurons and astrocytes. J Biol Chem 281:18081-18089.

Carlezon Jr WA, Thome J, Olsen VG, Lane-Ladd SB, Brodkin ES, Hirol N, Duman RS, Neve RL, Nestlter EJ (1998) Regulation of cocaine reward by CREB. Science 282:2272-2275.

Carlezon Jr WA, Duman RS, Nestler EJ (2005) The many faces of CREB. Trends Neurosci 28:436-445.

Chefer VI, Czyzyk T, Bolan EA, Moran J, Pintar JE, Shippenberg T (2005) Endogenous $\kappa$-opioid receptor systems modulate mesoaccumbal dopamine dynamics and vulnerability to cocaine. J Neurosci 25:5029-5037.

Clarke S, Czyzyk T, Ansonoff M, Nitsche JF, Hsu MS, Nilsson L, Larsson K, Borsodi A, Toth G, Hill R, Kitchen I, Pintar JE (2002) Autoradiography of opioid and ORL1 ligands in opioid receptor triple knockout mice. Eur J Neurosci 16:1705-1715.

Contarino A, Papaleo F (2005) The corticotrophin-releasing factor receptor-1 pathway mediates the negative affective states of opiate withdrawal. Proc Natl Acad Sci USA 102:18649-18654.

Dalvi A, Lucki I (1999) Murine models of depression. Pyschopharmacology 147:14-16.

de Kloet ER, Joels M, Holsboer F (2005) Stress and the brain: from adaptation to disease. Nat Rev Neurosci 6:463-475.

Dewire SM, Ahn S, Lefkowitz RJ, Shenoy SK (2007) Beta-arrestins and cell signaling. Annu Rev Physiol 69:483-510.

Gallagher TF, Seibel GL, Kassis S, Laydon JT, Blumenthal MJ, Lee JC, Lee D, Boehm JC, Fier-Thompson SM, Abt JW, Soreson ME, Smietana JM, Hall RF, Garigipati RS, Bender PE, Erhard KF, Krog AJ, Hofmann GA, Sheldrake PL, McDonnell PC, Kumar S, Young PR, Adams JL (1997) Regulation of stress-induced cytokine production by pyridinylimidazoles; inhibition of CSBP kinase. Biorg Med Chem 5:49-64.

Hebert MA, Serova LI, and Sabban EL (2005) Single and repeated immobilization stress differentially trigger induction and phosphorylation of several transcription factors and mitogen-activated protein kinases in the rat locus coeruleus. J Neurochem 484-498.

Hellemans KGC, Everitt BJ, Lee JLC (2006) Disrupting reconsolidation of conditioned withdrawal memories in the basolateral amygdale reduces suppression of heroin seeking in rats. J Neurosci 26:12694-12699.

Herman JP, Mueller NK, Figueiredo H (2004) Role of GABA and glutamate circuitry in hypothalmo-pituitary-adrenocortical stress integration. Ann NY Acad Sci 1018:35-45.

Holsboer F (2000) The stress hormone system is back on the map. Neurophychopharmacology 23:477-501.

Kam AY, Chan AS, Wong YH (2004) Kappa-opioid receptor signals through Src and focal adhesion kinase to stimulate c-Jun N-terminal kinases in transfected COS-7 cells and human monocytic THP-1 cells. J Pharmacol Exp Ther 310:301-310.

Koh MT, Wilkins EE, Bernstein IL (2003) Novel tastes elevate c-fos expression in the central amygdala and insular cortex: implication for taste aversion learning. Behav Neurosci 117:1416-1422.

Kreek MJ, Koob GF (1998) Drug dependence: stress and dysregulation of brain reward pathways. Drug Alcohol Depend 51:23-47.

Kreibich AS, Blendy JA (2004) The role of cAMP response element-binding proteins in mediated stress-induced vulnerability to drug abuse. J Neurosci 24:6686-6692.

Lucki I, Dalvi A, Mayorga AJ (2001) Sensitivity to the effects of pharmacologically selective antidepressants in different strains of mice. Psychopharmacology 155:315-322.

Mague SD, Pliakas AM, Todtenkopf MS, Tomasiewicz HC, Zhang Y, Stevens Jr WC, Jones RM, Portoghese PS, Carlezon Jr WA (2003) Antidepressant-like effects of kappa-opioid receptor antagonists in the forced swim test in rats. J Pharmacol Exp Ther 305:323-330. 
Mansour A, Khachaturian H, Lewis ME, Akil H, Watson SJ (1987) Audioradiographic differentiation of $\mathrm{mu}$, delta, and $\kappa$-opioid receptors in the rat forebrain and midbrain. J Neurosci 7:2445-2464.

McLaughlin JP, Marton-Popovici M, Chavkin C (2003a) $\kappa$-Opioid receptor antagonism and prodynorphin gene disruption block stress-induced behavioral responses. J Neurosci 23:5674-5683.

McLaughlin JP, Xu M, Mackie K, Chavkin C (2003b) Phosphorylation of a carboxyl-terminal serine within the kappa-opioid receptor produces desensitization and internalization. J Biol Chem 278:34631-34640.

McLaughlin JP, Myers LC, Zarek PC, Caron MC, Lefkowitz RJ, Czyzyk T, Pintar PE, Chavkin C (2004) Prolonged kappa opioid receptor phosphorylation mediated by G-protein receptor kinase underlies sustained analgesic tolerance. J Bio Chem 279:1810-1818.

McLaughlin JP, Li S, Valdez J, Chavkin TA, Chavkin C (2006) Social defeat stress-induced behavioral responses are mediated by the endogenous kappa opioid system. Neurophyschopharmacology 31:1241-1248.

Mello NK, Mendelson JH (1997) Cocaine's effect on neuroendocrine systems, clinical and preclinical studies. Pharmacol Biochem Behav 57:571-599.

Newton SS, Thome J, Wallace TL, Shirayama Y, Schlesinger L, Sakai N, Chen J, Neve R, Nestler EJ, Duman RS (2002) Inhibition of cAMP response element-binding protein or dynorphin in the nucleus accumbens produces an antidepressant-like effect. J Neurosci 22:10883-10890.

Paxinos G, Franklin KBJ (2004) The mouse brain in stereotaxic coordinates, pp 23-36. San Diego: Academic.

Peppel K, Boekhoff I, McDonald P, Breer H, Caron MG, Lefkowitz RJ (1997) G protein-coupled receptor kinase 3 (GRK3) gene disruption leads to loss of odorant receptor desensitization. J Biol Chem 272:25425-25428.

Pliakas AM, Carlson RR, Neve RL, Konradi C, Neslter EJ, Carlezon Jr WA (2001) Altered responsiveness to cocaine and increased immobility in the forced swim test associated with elevated cAMP response elementbinding protein expression in nucleus accumbens. J Neurosci 21:7397-7403.

Porsolt RD, Le Pichon M, Jalfre M (1977) Depression: a new animal model sensitive to antidepressant treatments. Nature 266:730-732.

Prasad HC, Zhu CB, McCauley JL, Samuvel DJ, Ramamoorthy S, Shelton RC, Hewlett WA, Sutcliffe JS, Blakely RD (2005) Human serotonin transporter variants display altered sensitivity to protein kinase $G$ and p38-mitogen-activated protein kinase. Proc Natl Acad Sci USA 102: $11545-11550$

Rahmouni K, Haynes WG, Morgan DA, Mark AL (2003) Role of melanocortin-4 receptors in mediated renal sympathoactivation to leptin and insulin. J Neurosci 23:5998-6004.

Rolli M, Kotlyarov A, Sakamoto KM, Gaestel M, Neininger A (1999) Stressinduced stimulation of early growth response gene-1 by $\mathrm{p} 38 / \mathrm{stress}$ activated protein kinase 2 is mediated by a cAMP-responsive element in a MAPKAP kinase2-independent manner. J Biol Chem 274:19559-19564.

Rumbaugh G, Adams JP, Kim JH, Huganir RL (2006) SynGAP regulates synaptic strength and mitogen-activated protein kinases in cultured neurons. Proc Natl Acad Sci USA 103:4344-4351.

Samuvel DJ, Jayanthi LD, Bhat NR, Ramaoorthy S (2005) A role for p38 mitogen-activated protein kinase in the regulation of the serotonin transporter, evidence for distinct cellular mechanism involved in transporter surface expression. J Neurosci 25:29-41.

Sante AB, Nobre MJ, Brandao ML (2000) Place aversion induced by blockade of mu or activation of kappa opioid receptors in the dorsal periaqueductal gray matter. Behav Pharmacol 11:583-589.

Shen CP, Tsimberg Y, Salvadore C, Meller E (2004) Activation of Erk and JNK MAPK pathways by acute swim stress in rat brain regions. BMC Neurosci 5:36.

Shenoy SK, Lefkowitz RJ (2005) Seven-transmembrane receptor signaling through beta-arrestin. Sci STKE 308, cm10.

Shippenberg TS, Chefer VI, Zapata A, Heidbreder CA (2001) Modulation of the behavioral and neurochemical effects of psychostimulants by kappaopioid receptor systems. Ann NY Acad Sci 937:50-73.

Sindreu CB, Scheiner ZS, Storm DR (2007) Ca2+-stimulated adenylyl cyclases regulate ERK-dependent activation of MSK1 during fear conditioning. Neuron 53:79-89.

Spanagel R, Almeida OF, Bartl C, Shippenberg TS (1994) Endogenous kappa-opioid systems in withdrawal: role in aversion and accompanying changes in mesolimbic dopamine release. Psychopharmacology (Berl) 115:121-127.

Thomas GM, Huganir RL (2004) MAPK cascade signaling and synaptic plasticity. Nat Rev Neurosci 5:173-183.

Vaught JL, Takemori AE (1979) Differential effects of leucine and methionine enkephaline on morphin-induced analgesia, acute tolerance and dependence. J Pharmacol Exp Ther 208:86-90.

Vortherms TA, Roth BL (2006) Salvinorin A: from natural product to human therapeutics. Mol Interv 6:257-265.

Xu M, Petraska M, McLaughlin JP, Westenbroek RE, Caron MG, Lefkowitz RJ, Czyzyk TA, Pintar JE, Terman GW, Chavkin C (2004) Neuropathic pain activated the endogenous $\kappa$-opioid system in mouse spinal cord and induces opioid receptor tolerance. J Neurosci 24:4576-4584.

Xu M, Bruchas MR, Ippolito DL, Gendron L, Chavkin C (2007) Sciatic nerve ligation-induced proliferation of spinal cord astrocytes is mediated by $\kappa$ opioid activation of p38 mitogen-activated protein kinase. J Neurosci 10:2570-2581.

Young PR, McLaughlin MM, Kumar S, Kassis S, Doyle ML, McNulty D, Gallagher TF, Fisher S, McDonnell PC, Carr SA, Huddleston MJ, Seibel G, Porter TG, Livi GP, Adams JL, Lee JC (1997) Pyridinyl imidazole inhibitors of p38 mitogen-activated protein kinase bind in the ATP site. J Biol Chem 272:12116-12121.

Zhen X, Du W, Roman AG, Friedman E, Harvey JA (2001) The p38 mitogen-activated protein kinase is involved in associative learning in rabbits. J Neurosci 21:5513-5519. 